\title{
DIRECTIONS TO INCREASE THE POTENTIAL OF RAW WOOD AS A RENEWABLE ENERGY SOURCE (ON THE EXAMPLE OF THE ADMINISTRATIVE RAION)
}

\author{
Dmitry VOROBYOV
}

Belarusian State University, Minsk, Belarus

dzm.varabyou@gmail.com

\begin{abstract}
The description of current research in the area of evaluation of the raw wood energy potential was submitted. For example, the article reviewes the directions to increase potential of raw wood as a renewable energy source in Zhlobin administrative raion, that imply the greater use of non-liquid part of the timber, harvesting low-value tree species and creation of fuel-energy plantations.
\end{abstract}

Key words: wood fuel, renewable energy, bioenergy, energy plantations

UDC: 620.95

\section{ШЛЯХИ ПІДВИЩЕННЯ ПОТЕНЦІАЛУ ДЕРЕВНОЇ СИРОВИНИ ЯК ПОНОВЛЮВАНОГО ДЖЕРЕЛА ЕНЕРГІЇ (НА ПРИКЛАДІ АДМІНІСТРАТИВНОГО РАЙОНУ)}

\author{
Дмитро ВОРОБЙОВ \\ Білоруський державний університет, Мінськ, Білорусь \\ dzm.varabyou@gmail.com
}

Анотація: У роботі дана коротка характеристика сучасних досліджень в галузі оцінки енергетичного потенціалу деревної сировини. На прикладі Жлобінського адміністративного району розглянуті шляхи підвищення потенціалу деревної сировини як поновлюваного джерела енергії за рахунок більш повного використання неліквідної частині деревини, заготовки малоцінних деревних порід і створення паливно-енергетичних плантацій.

Ключові слова: деревне паливо, поновлювані джерела енергії, біоенергетика, енергетичні плантації

УдК: 620.95

\section{ПУТИ ПОВЫШЕНИЯ ПОТЕНЦИАЛА ДРЕВЕСНОГО СЫРЬЯ КАК ВОЗОБНОВЛЯЕМОГО ИСТОЧНИКА ЭНЕРГИИ (НА ПРИМЕРЕ АДМИНИСТРАТИВНОГО РАЙОНА)}

\author{
Дмитрий ВОРОБЬЕВ \\ Белорусский государственный университет, Минск, Беларусь \\ dzm.varabyou@gmail.com
}

\begin{abstract}
Аннотация: В работе дана краткая характеристика современных исследований в области оценки энергетического потенциала древесного сырья. На примере Жлобинского административного района рассмотрены пути повышения потенциала древесного сырья как возобновляемого источника энергии за счет более полного использования неликвидной части древесины, заготовки малоценных древесных пород и создания топливно-энергетических плантаций.
\end{abstract}

Ключевые слова: древесное топливо, возобновляемые источники энергии, биоэнергетика, энергетические плантации

Удк: 620.95

Введение. Постановка проблемы. Одним из важнейших элементов устойчивого развития любого государства является его энергетическая безопасность, которая выражается в доле использования собственных энергоресурсов для производства тепловой и электрической энергии. В области обеспечения энергетической независимости Республики Беларуси поставлены задачи снизить энергоемкость ВВП (не менее чем на 60 \% в 2020 г. к уровню 2005 г.), обеспечить экономию энергоресурсов (не менее 5,2 млн. т.у.т. в 2016-2020 гг.), увеличить долю использования собственных энергоресурсов для производства тепловой и электрической энергии (не менее 32 \% в 2020 г.) [9]. На начало 2015 г. доля местных топливно-энергетических ресурсов в балансе котельно-печного топлива республики составила 23,9 \% [8]. Производство природных видов топливно-энергетических ресурсов в Беларуси представлено главным образом добычей торфа (2,3 млн. т ежегодно), нефти (1,6 млн. т ежегодно, сокращается), попутного газа (228 млн. м³ ежегодно), заготовкой дров (6,1 млн. плотных м³, возрастает) 
[14]. При этом ежегодно импортируется более 20 млн. т сырой нефти и 20 млрд. м³ природного газа, что является основной причиной отрицательного сальдо внешней торговли. Задача по увеличению доли местных видов энергетических ресурсов и возобновляемых источников энергии является первостепенной для Беларуси.

$$
\text { Собственные ресурсы невозобнов- }
$$

ляемого углеводородного сырья представлены незначительными запасами (нефть, бурые угли) или не могут рассматриваться в качестве топлива по ряду причин экономического и экологического характера (торф, горючие сланцы), а использование в больших масштабах возобновляемых источников энергии представляется затруднительным в силу природных особенностей территории. Наиболее значимым видом топлива в общем балансе местных топливноэнергетических ресурсов является древесная биомасса, которая характеризуется значительной территориальной рассредоточеностью.

Анализ последних исследований и публикаций. Накопленный мировой опыт получения энергии из древесного сырья показывает, что использование последнего является не только экологическибезопасным, ноиконкурентоспособным в сравнении с традиционными видами топлива, a следовательно - экономически выгодным. Значительных успехов в области древесной биоэнергетики добились развитые лесные государства Европейского Союза, множество выполненных исследований которых может быть объединено программой «Энергия биомассы в Европе» [3], имевшей своей целью совершенствование методологии оценки ресурсов биомассы для энергетических целей путем унификации методик. В числе основных результатов проекта: сравнительный анализ существующих оценок ресурсов биомассы (методология, используемый набор данных) на глобальном, европейском, региональном и национальном уровне, с целью выявления общих подходов, а также важных различий; разработка и практическая апробация согласованной методики исследования, основанной на общих методологических обсуждениях и наборе данных; обобщение, критический обзор и рекомендации для дальнейшего совершенствования оценки потенциала биомассына основеполученных фактических данных. Отличительная черта европейских исследований [1, $2,3]$ - ориентация на потребителя, акцент на оценку экономической доступности биомассы на уровне насаждения, широкое использование сценариев и современных ГИС-методов.

В странах СНГ наибольших успехов в области оценки биоэнергетических ресурсов в целом и древесного сырья в частности достигли Россия и Украина.Исследования выполняются по европейским методикам в рамках международных проектов, носят региональный характер, акцентированы на потребителя и приурочены к энергодефицитным областям (Ленинградская, Калининградская, Мурманская, Архангельская области, Республика Карелия и другие) $[5,18,20]$.
В Беларуси вопросам использования древесного сырья в энергетических целях посвящены работы преимущественно специалистов технического профиля, лесоводческой отрасли, которые практически не затрагивают вопросы территориального распределения ресурса древесного сырья, не являются комплексными. Как правило, методики оценки потенциала последнего предполагают оценку с использованием данных о планируемых лесозаготовительных работах (учет сортименто-сортной структуры насаждений), их теплотворной способности и других $[4,11,12,13,19]$. Исследования не затрагивают вопросы возможности увеличенияпотенциаладревесногосырья(повышение продуктивности лесов, создание энергетических плантаций). Последние представлены в работах [16, $17,21]$ и могут быть использованы при комплексном подходе к оценке биоресурсного потенциала древесного сырья как возобновляемого источника энергии. Исследования также носят региональный характер, информация об энергетической обеспеченности территории предоставлена преимущественно в разрезе административных областей или лесохозяйственных учреждений (границы последних практически не совпадают), что усложняет принятие управленческих решений, направленных на рациональное использование имеющегося потенциала древесного сырья.

Выполняемые в настоящее время исследования не в полной мере удовлетворяют современные запросы практики, поскольку решают лишь частные задачи - рассматривают потенциал биомассы на региональном уровне исследования, не в полной мере учитывают возможности его увеличения.

Формулировка целей статьи. Постановка задачи. В работе представлены основные направления повышения энергетического потенциала древесного сырья как возобновляемого источника энергии, которое является частью комплексной оценки ресурсов древесного сырья, перспективного к использованию в энергетических целях, на уровне административного района. Последняя заключается в анализе баланса производства и потребления древесного топлива, оценке его ресурсной базы, а также возможности ее увеличения. Увеличение потенциала древесного сырья как источника энергии возможно за счет: более полного использования неликвидной части древесины, а также древесного отпада, которые в настоящее время ограничено вовлечены в хозяйственный оборот; заготовки в энергетических целях малоценных насаждений; создания топливно-энергетических плантаций древесных пород. Работа выполнена на примере Жлобинского административного района Гомельской области (Республика Беларусь).

\section{Изложение основного}

материала

исследования. Суммарное потребление древесного топлива в Жлобинском районе в 2011-2014 гг. имело тенденцию к росту с 40,0 до 72,9 тыс. м³ (по данным Жлобинского районного исполнительного комитета) и запланировано на 2015 г. в объеме 47,6 тыс. м³ на 34,7 \% ниже показателя 2014 г. Ожидается, что 
к 2020 г. объем использования древесного топлива составит 60,8 тыс. м³. Основным потребителем древесного топлива является КДУП «Теплосервис» (более 50,0 \% всего потребления древесного топлива района), которое осуществляет работы по обслуживанию и эксплуатации котельных и тепловых сетей района. На балансе предприятия находится 35 объектов, которые в 2014 г. на производство тепловой энергии израсходовали 6,7 тыс. т.у.т. (в т.ч. 6,5 тыс. т.у.т. - местные виды топлива). Около 40,0 \% общего потребления древесного топлива отпускается на нужды населения.

Производство древесного топлива осуществляется главным образом на базе трех организаций: ГЛХУ «Жлобинский лесхоз» (топливные дрова, заготавливаемые при плановых рубках леса), ООО «ОКА» (отходы деревообработки) и КЖУП «Уником» (отходы лесозаготовки). С 2011 по 2014 г. объемы производства древесного топлива возросли с 42,0 до 93,8 тыс. м $^{3}$, а на 2015 г. запланированы на уровне 98,0 тыс. м³ . Имевший место в 2012-2013 гг. отрицательный баланс потребления древесного топлива сменился профицитом, который был достигнут благодаря вовлечению в топливный баланс района новых видов древесного сырья - отходов деревообработки (25,0 тыс. $\left.\mathbf{M}^{3}\right)$ и лесозаготовки $\left(23,0\right.$ тыс. $\left.\mathbf{M}^{3}\right)$.

Определение потенциально доступного объема древесного топлива выполнено по методике [19]. Общая площадь лесного фонда района составляет 80,6 тыс. га [7]. Общий запас насаждений составляет 15,8 млн. м ${ }^{3}$ (молодняки - 9,0 \%, средневозрастные $53,6 \%$, приспевающие - 25,6 \%, спелые и перестойные - $10,8 \%$ ) и имеет тенденцию к росту (увеличение на 0,8 млн. м $^{3}$ в сравнении с 2010 г.). Объем заготовки древесины ГЛХУ «Жлобинский лесхоз» (99% площади лесного фонда района) по всем видам рубок за 2014 г. составил 150,0 тыс. м³ , в т.ч. по рубкам главного пользования - 75,1 тыс. м ${ }^{3}$ (в 2011 г. соответственно - 114,3 и 37,7 тыс. м $^{3}$ ). С учетом сохранения размера лесопользования на данном уровне, технически доступный объем древесного топлива (лесосечные отходы, тонкомерная древесина) составит порядка 20,0-25,0 тыс. м $^{3}$, а также дополнительно - 60,0-65,0 тыс. $\mathrm{M}^{3}$ топливных дров. Суммарный возможный объем древесного топлива составит 80,0-90,0 тыс. м $^{3}$ (17,5-20,0 тыс. т.у.т.). Неоптимальная возрастная структура лесов (молодняки - 20,7 \% от площади лесопокрытых земель, средневозрастные - 50,1 \%, приспевающие-20,7 \%, спелые и перестойные-8,5\%) не позволяет в полном объеме использовать текущий

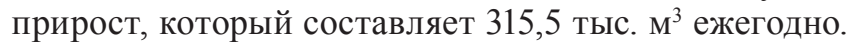
Значительная часть древесного отпада, который может рассматриваться в качестве топливного резерва, уже заготавливается при проведении рубок промежуточного пользования. Следовательно, вовлечение в последние годы в топливный баланс отходов лесозаготовки с одной стороны свидетельствует о более полном использовании неликвидной части древесины, с другой - о незначительном резерве увеличения потенциала древесного топлива. Согласно проекта ведения лесного хозяйства района, по мере приближения возрастной структуры лесов к оптимальной расчетная лесосека только по рубкам главного пользования предположительно возрастет до 95,0 тыс. м $^{3}$ к 2020 г. Увеличится и потенциал древесного топлива, который имеет высокую территориальную рассредоточенность, относительную удаленность от мест потребления, а также значительный период оборота рубки.

Одним из направлений увеличения потенциала древесного топлива следует считать создание топливно-энергетических плантаций (ТЭП) древесных пород с целью целенаправленного выращивания древесного сырья в энергетических целях. С 2007 г. на территории района создано 13 энергетических плантаций, общая площадь которых составляет 19,1 га. Следует отметить, что данные насаждения не в полной мере соответствуют требованиям [16] - имеют небольшую площадь (0,53,8 га), значительно удалены от предполагаемого потребителя (расстояние вывозки превышает 60 км), не могут быть объединены в блоки по причине территориальной рассредоточенности.

В качестве территориального ресурса для создания новых ТЭП могут быть использованы малопродуктивные и неиспользуемые сельскохозяйственные земли, которые определены по результатам кадастровой оценки земель сельскохозяйственных организаций [10]. Согласно схеме землеустройства Жлобинского района, в настоящее время под лесопользование планируется передать 157,4 га земель. Анализ результатов кадастровой оценки сельскохозяйственных земель, а также рекомендаций по оптимизации их землепользования позволил дополнительно выявить 510,3 га земель, которые также могут быть использованы в энергетических целях: пахотные земли, получение продукции на которых характеризуется отрицательным чистым доходом (12 участков, 242,0 га) (были рекомендованы к передаче под облесение, но используются в сельскохозяйственном производстве); закустаренные луговые земли (неиспользуемые земли, доля кустарников $>25,0$ \%) (16 участков, 268,3 га).

Указанные земли соответствуют критериям, предъявляемым к лесокультурным площадкам для создания топливно-энергетических плантаций быстрорастущих древесных пород [16], и в первую очередь должны рассматриваться с позиций биоэнергетики. Проанализировав исследования белорусских ученых в области технологии и эффективности создания топливно-энергетических плантаций $[15,17,21]$, было установлено, что выращивание на указанных площадках в энергетических целях сосны (чистые насаждения) позволит получить дополнительно 100,0140,0 тыс. $\mathbf{M}^{3}$ древесного топлива к возрасту рубки (до 7,0 тыс. м $^{3}$ древесины или 1,5 тыс. т.у.т. ежегодно при условии равновременного оборота плантаций). Отличительной особенностью последнего будет высокая концентрация ресурса, сравнительно небольшой период рубки (20-25 лет). Также следует 
Таблиияа 1

Площадь реконструкции низкопродуктивных и малоценных древостоев II группы лесов в разрезе лесничеств Жлобинского ГЛХУ

\begin{tabular}{|l|c|c|c|c|c|c|c|c|}
\hline \multirow{2}{*}{ Регион } & \multicolumn{2}{|c|}{ Хвойные } & \multicolumn{2}{c|}{ Твердолиственные } & \multicolumn{2}{c|}{ Мягколиственные } & \multicolumn{2}{c|}{ Всего } \\
\cline { 2 - 9 } & га & $\%$ & га & $\%$ & га & $\%$ & га & $\%$ \\
\hline Щедринское & 790,6 & 26,4 & 28,8 & 100,0 & 1309,9 & 100,0 & 2129,3 & 49,1 \\
\hline Дворищанское & 1037,6 & 31,0 & 156,7 & 76,3 & 866,6 & 100,0 & 2060,9 & 46,6 \\
\hline Краснобережское & 649,3 & 15,7 & 90,2 & 52,7 & 1581,3 & 100,0 & 2320,8 & 39,4 \\
\hline Коротковичское & 639,6 & 20,3 & 21,1 & 82,7 & 964,6 & 100,0 & 1625,3 & 39,3 \\
\hline Хальчанское & 336,4 & 27,7 & 80,9 & 57,5 & 534,0 & 100,0 & 951,3 & 50,4 \\
\hline Приберезинское & 944,0 & 21,2 & 56,3 & 66,7 & 1520,4 & 100,0 & 2520,7 & 41,6 \\
\hline Стрешинское & 255,6 & 28,2 & - & - & 507,8 & 100,0 & 763,4 & 53,9 \\
\hline Солонское & 78,5 & 9,5 & 9,5 & 100,0 & 221,7 & 100,0 & 309,7 & 29,2 \\
\hline Всего & 4731,6 & 22,5 & 443,5 & 66,6 & 7506,3 & 100,0 & 12681,4 & 43,4 \\
\hline
\end{tabular}

отметить, в Жлобинском районе насчитывается порядка 5,8 тыс. га земель [6], покрытых древеснокустарниковой растительностью, которые при необходимости также могут быть использованы под энергетические нужды.

Создание топливно-энергетических плантаций древесных пород не может служить инструментом увеличения потенциала древесного топлива на начальном этапе (до достижения возраста рубки первых насаждений). В краткосрочной перспективе в качестве топлива может быть использовано древесное сырье, образующееся при проведении рубок реконструкции с целью повышения продуктивности лесов. Согласно [17], сплошные рубки реконструкции с созданием чистых насаждений сосны предлагается проводить для низкопродуктивных древостоев (оценка древостоев менее 50 баллов) хвойных и твердолиственных пород, а также всех древостоев мягколиственных пород. Необходимо отметить, проведение сплошных рубок реконструкции в лесах I группы не представляется возможным в силу их высокой экологической значимости. Леса II группы являются эксплуатационными, следовательно, лесовыращивание должно быть ориентировано на максимальную эффективность (выращивание хозяйственно ценных древесных пород). Учитывая вышеизложенное, установлено, что Жлобинском районе реконструкции может быть подвергнуто 12,7 тыс. га или 43,4 \% насаждений эксплуатационной группы лесов (таблица).

В таблице не приведена информация для Луговирнянского лесничества, т.к. все лесопокрытые земли отнесены к I группе лесов. Породный состав лесов II группы возвышенной центральной части района (Краснобережское, Коротковичское, Приберезинское и Солонское лесничества) в наибольшей мере соответствует условиям местопроизрастания (коэффициент использования плодородия почв в среднем более 0,7). Повышение продуктивности путем проведения сплошных рубок реконструкции требуется на 30-40 \% лесопокрытых земель. Для Щедринского, Дворищанского, Хальчанского и Стрешинского лесничества этот показатель выше - 45-55 \% эксплуатационных лесов.

Выводы и перспективы дальнейших исследований. Использование древесного сырья в качестве топлива является одним из основных инструментов обеспечения энергетической безопасности Беларуси. Несмотря на значительные запасы лесных ресурсов, должное внимание должно быть уделено комплексному изучению потенциала древесного топлива, перспективам его увеличения. К числу последних следует отнести более полное использование неликвидной части древесины, насаждений низкопродуктивных и малоценных древесных пород, создание топливно-энергетических плантаций. Выполненная на примере Жлобинского административного района оценка энергетического потенциала древесного сырья позволяет считать древесное топливо перспективным источником возобновляемой энергии для исследуемого района. Приведенная в работе модель может использоваться при выполнении исследований по оценке потенциала древесного топлива других регионов.

\section{References:}

1. Fischer G., Hizsnyik E., Prieler S., Velthuizen H. Assessment of biomass potentials for bio-fuel feedstock production in Europe: Methodology and results. Work Package 2-Biomass potentials for bio-fuels: sources, magnitudes, land use impacts. Deliverable D6: Methodology and assessment of biomass potentials in EU27+ under alternative future scenarios. July 2007, $81 \mathrm{p}$.

2. Parrika M. Biosims - A method for the Estimation of Woody Biomass for Fuel in Sweden. Swedish Univ. of Agricult. Sciences. Doct. thesis, Uppsala. 1997. 
3. Status of Biomass Resource Assessments. Version 3. Del. No: D 3.6 Issue/Rev: 1. November, 2010.

4. Baginskij V. F. Potencial ispol'zovaniâ drevesnoj massy dlâ topliva v Respublike Belarus' [Use of wood for fuel: potential in the Republic of Belarus]. Prirodnye resursy [Natural resources], 2005, No 4, pp. 44-50. (In Russian).

5. Geletuha G. G., Želêzna T. A., Žovmìr M. M., ta in. Ocìnka energetičnogo potencìalu bìomasi v Ukraïnì [Evaluation of biomass energy potential in Ukraine]. Promyšlennaâ teplotehnika [Industrial heat engineering], 2010, P. 32, No 6., pp. 58-65. (In Ukrainian).

6. The State Land Cadastre of the Republic of Belarus (as of January 1, 2015). The State Property Committee of the Republic of Belarus. Minsk, 2015, 57 p. (In Russian).

7. The State Forest Cadastre of the Republic of Belarus (as of 1 January 2015) [Electronic source]. Minsk, 2015. (In Russian).

8. The Department for Energy Efficiency of the State Standardization Committee of the Republic of Belarus. Access mode: http://energoeffekt.gov.by . Access date: 25.04.2015. (In Russian).

9. Directive of the President of the Republic of Belarus No 3 "Economy and thrift - the main factors of economic security of the state" dated 14 June 2007 [Electronic source]. Access mode: http://president.gov.by. Access date: 25.04.2015. (In Russian).

10. Kuznecov G. I., Moroz G. M., Zen'kovič A. I. et al. Kadastrovaâ ocenka zemel'sel'skohozâjstvennyh organizacij i krest'ânskih (fermerskih). Raspredelenie ploŝadi obrabatyvaemyh zemel' po blagopriâtnosti dlâ zemledeliâ [Cadastral valuation of lands of agricultural organizations and peasant (farm). The distribution of cultivated land by favorability for agriculture]. Minsk, Committee on Land Resources, Geodesy and Cartography at the Council of Ministers of the Republic of Belarus, 2002, 160 p. (In Russian).

11. Kovalevič A. I., Usenâ V. V. Rol' lesnyh resursov v toplivno-ènergetičeskom komplekse Belarusi [The role of forest resources in the fuel and energy complex of Belarus]. Trudy Sankt-Peterburgskogo naučno-issledovatel'skogo instituta lesnogo hozâjstva [Proceedings of the St. Petersburg Forestry Research Institute], 2013, No 1, pp. 26-28. (In Russian).

12. Kundas S. P., Poznâk S. S., Švec L. V. Vozobnovlâemye istočniki ènergii [Renewable energy sources]. Minsk, 2009, 314 p. (In Russian).

13. Matvejko A. P., Protas P. A. Prognoz real'nyh fizičeskih resursov drevesnogo syr'â dlâ ènergetičeskih celej i ih territorial'noe raspredelenie [Forecast of actual physical resources of wood raw material for energy purposes and their territorial distribution]. Trudy BGTU [Proceedings of BSTU], Minsk, 2011, No 2 (140), pp. 140-142. (In Russian).

14. National statistical Committee of the Republic of Belarus. Access mode: http://belstat.gov.by. Access date: 25.04.2015. (In Russian).

15. Normativnye materialy dlâ taksacii lesa Belorusskoj SSR [Regulatory materials for forest inventory of the Byelorussian SSR]. Ed.: V.F. Baginskij. Moscow, 1984, 308 p. (In Russian).

16. Rekomendacii po sozdaniû toplivno-ènergetičeskih plantacij bystrorastuŝih drevesnyh porod [Guidelines for creating fuel and energy plantations of fast-growing tree species]. Minsk: The Forest Institute of NAS of Belarus, 2010, 15 p. (In Russian).

17. Rusalenko A. I. Lesa Belarusi: èkologiâ, struktura, produktivnost' [Belarusian forests: ecology, structure, productivity]. Minsk, 2012, 346 p. (In Russian).

18. Sidorenko G. I., Sidorenko D. G. Model' optimizacii i racional'nogo ispol'zovaniâ vozobnovlâemyh ènergetičeskih resursov Karelii [Model for optimization and rational use of renewable energy resources of Karelia]. Èkologiâ promyšlennogo proizvodstva [Industrial ecology], 2007, No 4, pp. 10-22. (In Russian).

19. Fedorenčik A. S., Lednickij A. V. Ėnergetičeskoe ispol'zovanie nizkokačestvennoj drevesiny i drevesnyh othodov [The energy use of low quality wood and wood waste]. Minsk, 2010, 445 p. (In Russian).

20. Holodkov V. S. Ispol'zovanie drevesnoj biomassy v bioènergetičeskih proektah severo-zapadnogo regiona Rossijskoj Federacii [The use of woody biomass in bioenergy projects in North-Western region of the Russian Federation]. Vozobnovlâemaâ ènergetika dlâ Severo-zapada Rossii [Renewable energy for the North-West of Russia], Saint Petersburg, 2005, pp. 22-28. (In Russian).

21. Štukin S. S. Uskorennoe vyrasiivanie sosny, eli i listvennicy na lesnyh plantaciâh [Rapid growing of pine, spruce and larch at forest plantations]. Minsk, 2004, 242 p. (In Russian). 